\title{
WHAT'S FOR DINNER? \\ GENDERED DECISION-MAKING AND ENERGY EFFICIENT COOKSTOVES IN BENUE STATE, NORTH CENTRAL NIGERIA
}

\author{
PETER ATAGHER ${ }^{1}$, MIKE CLIFFORD ${ }^{1}$, SARAH JEWITT $^{2}$ \& CHARLOTTE RAY $^{1}$ \\ ${ }^{1}$ Faculty of Engineering, University of Nottingham, UK \\ ${ }^{2}$ School of Geography, University of Nottingham, UK
}

\begin{abstract}
Solid biomass collection such as firewood rests mostly on women and children in settings where traditional fuels dominates household energy choices. A 2015 World Health Organisation (WHO) report estimated that 3.5 million people globally rely on solid biomass for cooking and heating using traditional and inefficient cookstoves. The report identified the practice as the major cause of indoor air pollution responsible for 4.3 million premature deaths globally and 70,000 deaths estimated in Nigeria. The study will discuss results from ongoing qualitative research investigating enablers for the uptake of improved cookstoves (ICS) in Benue State, North Central Nigeria. The researchers used interviews and household questionnaires to gain an understanding of gendered cooking responsibilities at the household level. The paper will highlight fuel choice and wider household responsibilities that affect the use of ICS. It further discusses households' sources of income and what duties are performed by spouses in the study area. Household decision-making regarding stove purchases and cooking preferences influencing the types of stove used for preparing food will be highlighted. The results suggest that households with shared responsibility for cooking and fuel choice help to enable women to make decisions on household energy use and have access to some basic financial resources. These appear to be important drivers for clean energy use. The study indicates that the inclusion of gender perspectives within energy policy has potential to promote the uptake of ICS with greater energy use efficiency and reduced levels of household air pollution among Nigeria's rural and urban population. Keywords: gender, household, responsibility, energy efficient cooking device (ICS).
\end{abstract}

\section{INTRODUCTION}

The Sustainable Development Goals (SGDs) are time-bound measurable objectives that seek to provide a safe, productive and equitable environment for everyone by 2030 [1]. SDG 7.1.2 seeks to promote affordable clean energy and cooking devices. In an effort to promote the adoption of improved cookstoves (ICS) the Global Alliance for Clean Cookstoves (GACC) was established in 2010 with the aim to foster the adoption of clean cookstoves and fuels in 100 million households by 2020 [2]. Currently, around 80 percent of households in Africa use firewood [3] and 69 percent of Nigerians use wood to meet their household energy needs [4]. Many household cook their food using biomass fuel on inefficient "traditional" cookstoves. Smith et al. [5], aver that emissions from these stoves contribute significantly to indoor air pollution. Bonjour et al. [6], estimate that 2.8 billion people rely on solid biomass fuel for cooking and heating globally, with air pollution from these cookstoves making a major contribution to 3.5 million premature deaths. According to a World Health Organization (WHO) report in 2014 [7], the estimated biomass reliant population had risen to 3 billion, with a corresponding 4.3 million premature deaths globally and 70, 000 deaths [4], estimated in Nigeria.

In many parts of Africa, the responsibility for firewood collection, processing, transportation and cooking falls mostly on women [8], who suffer when indoor air pollution from inefficient biomass cookstoves rises to unacceptable levels [9], [10]. Women and 
children who perform household firewood collection, transportation and processing tasks also face increased vulnerability to attack from people and wild animals. The time they have available for income generating opportunities may also be reduced [11].

An additional problem is that, gender division of labour within the household tend to place much of the burden of gathering cooking fuel on women and girls which creates inequalities in school attendance as boys are often allowed to go to school while girls are kept at home to help with domestic tasks [12]. According to Bolaji [13], the average weight of firewood carried by rural women in Sub-Sahara Africa is around $38 \mathrm{~kg}$ per trip. This burden often appears to increase, alongside other domestic duties, when men move out of the house in search of financial opportunities [14]. Kelekar and Nathan [12], suggest that, when the cost of an efficient cooking device is low compared to the opportunity costs associated with household duties, women are more likely to request one. As men often control household budgets, however, they may be unwilling to provide financial resources for an ICS with the result that women continue to use traditional and inefficient stoves. Treiber et al. [15], suggest that women's control over household decision-making and budgets are important elements influencing the likelihood of ICS uptake.

Treiber et al. [15] suggestion doesn't align with the energy ladder model which identified household income as the most influential factor determining type of cooking device [16]-[19]. The model assumes a direct correlation between income and fuel choices with households ultimately expected to shift to efficient fuels and clean cooking systems with financial progression. Studies by Bruce et al. [9] and Smith et al. [20], support the energy ladder model while Cecelski [21] argues that in low income households especially where women's economic purchasing power is low 'stacking' [22] is common whereby households use a combination of cooking devices to perform different cooking tasks. Joon et al. [23], suggest that improved understandings of the gendered dimensions of cooking priorities and preferences will be useful in helping to stimulate uptake of more energy efficient cooking devices since women use energy differently from men [24]. Nevertheless, traditional three stone fireplaces although energy inefficient, are widely used in both urban and rural areas in Nigeria [25] and are likely to remain attractive in areas where wood fuel can be collected free of cost.

The objective of this paper is to explore household-based gender divisions of labour and decision-making along with women's interest in access to ICS within the study areas of Benue State. We conclude that the greater inclusion of gender perspectives in ICS initiatives and energy policy more generally is likely to be valuable in helping to promote greater uptake of cleaner and more efficient cooking solutions among Nigeria's rural and urban population.

\section{MATERIALS AND METHODS}

\subsection{Country overview}

Nigeria's estimated population is around 140 million with an area of 923,769 square kilometres. The country is bordered on the West by the Republics of Benin and Niger; on the East by the Republic of Cameroon; on the North by Niger and Chad Republics and on the South by the Gulf of Guinea [26]. Although access to modern energy and cooking devices in Nigeria appears to be facilitated by government policies [27], these have failed to give consideration to gendered aspects of household energy use. Nigeria currently uses the 2006 census report as a baseline document for implementing energy policies and programmes at national and regional levels while institutional structures such as the Energy Commission of 


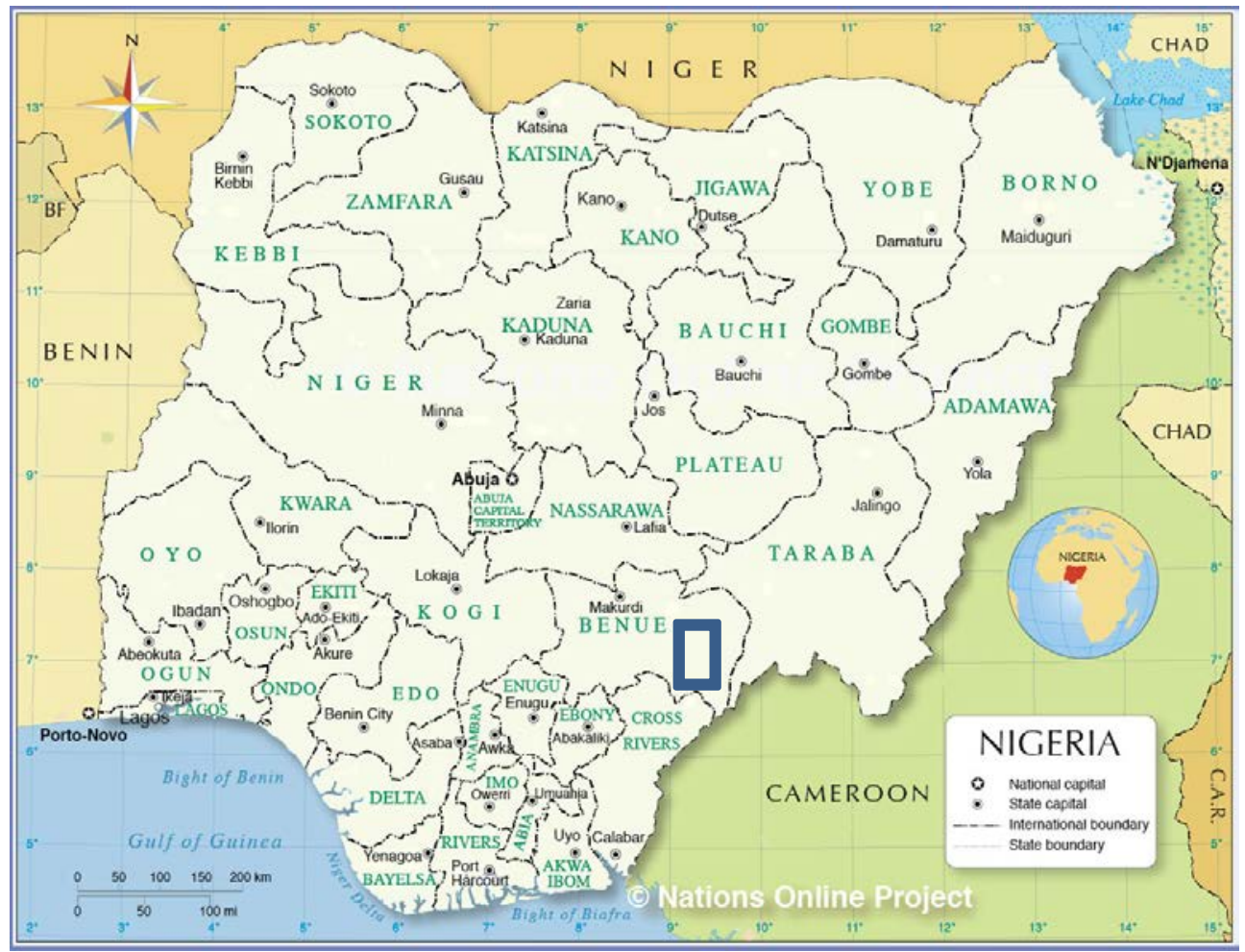

Figure 1: Map of Nigeria with the location of the study areas inserted [28].

Nigeria (ECN), Federal Ministry of Environment and Federal Ministry of Women Affairs monitor and create awareness of efficient and sustainable energy use.

\subsection{Study area}

Benue State is located in North Central Nigeria (Fig. 1) also known as the "Middle Belt" and is divided into three senatorial zones (North East, North West and Benue South) and twentythree local government areas. The state's vegetation is characterised a mixture of tall grasses and trees of average height [29]. The estimated population of the State is 4 million $(2,144,043$ male and 2,109,598 female) in an area of 30,800 square kilometres. The State was chosen for this study because of the high levels of firewood and charcoal use, and the researcher's knowledge of the communities and their language which enabled access to participants in different study sites. The ethnic make-up of the State is dominated by Tiv people who make up around $69 \%$ of the population $(1,484,649$ male and 1,361,345 female) [26]. Aside from firewood, charcoal is the second most widely used fuel and most households argue that it is less smoky than firewood. Charcoal trading is an important livelihood in the area as it is used different proportion in rural and urban areas [30]. 


\subsubsection{Rural survey}

Site selection for this study was carried out purposively [31], through the analysis of data from the 2008, 2010, 2013 and 2015 Nigeria Demographic Health Surveys (NDHS) on the types of cooking fuels used in the State coupled with the author's own knowledge of the study area. Efforts were made to include urban, peri-urban and rural sites. Study site 1 was located in an urban area within Makurdi, the State capital where households have access to different type of stoves. Due to a lack of ready access to wood fuel, most households in Study site 1 purchase their fuelwood and if households wish to obtain wood free of cost, they have to travel outside the community: a situation that provided useful insights into household responsibilities for obtaining fuel. Study sites 2 and 3 were located in peri-urban and rural areas respectively. In both sites, households travel within and outside of these communities to collect firewood at no cost.

\subsection{Data collection and analysis}

Data collection was undertaken in two phases (pilot and main fieldwork) after ethical approval was sought and obtained from the University of Nottingham (UK) research ethics review committee. The first phase involved negotiating access to the sites, becoming familiar with the settings and piloting the research instruments [32]. The sample for this study consist of 83 respondents. Of this figure, 58 respondents age between (19-70) representing about 70 percent consented to the study in the pilot phase which include mixed focus group discussions and household observations ( 35 female and 14 male) to provide insights in their cooking practices and methods of acquiring fuel. Semi-structured interviews were undertaken with nine ( 6 female and 3 male) community elders to understand existing cooking practice and their influence on the type of stoves and fuels used for cooking. The primary participants targeted during this phase were households with different demographic and economic characteristics that used different fuels and stoves for cooking and State stakeholders within the energy sector [33]. The themes from the pilot study were used to develop a household questionnaire and semi-structured interview guides that were used to elicit information from community elders and key informants. Drawing on work by Joon et al. [23] emphasis was placed on understanding cooking-related decision-making and how these influenced genderbased preferences for and uptake of different cooking devices including ICS. In addition, 21 household surveys (19 female and 2 male) were conducted to collect data on household demographics, fuel choices, cooking and fuel preferences, existing stove use and gendered household responsibilities for household budgets, cooking practices and stove/fuel choices. Drawing on interviews with government stakeholders and non-governmental organisation (NGOs), attention was also placed on the scale of energy policies and their impact on households in the study sites. To this end, interviews were conducted with 2 male government employees, (the scientific officer in the Energy Commission and a director within the Ministry of Women Affairs and Social Development) to understand energy policies and strategies that target households in Nigeria. To obtain more State-specific information, interviews were conducted with 2 male directors within the Ministry of Environment and Forestry and Urban Development to explore the energy policies and programmes affiliated to ICS interventions. In the second stage, 25 respondents representing 30 percent of the sampled population successfully participated. All qualitative data obtained were transcribed and exported into NVivo 10, coded and analyzed qualitatively while quantitative data were coded in Microsoft Excel 2013 and analyzed with a zero non-response. Thematic analysis 
was used to group emerging themes into descriptive themes. The results are presented in section 3.

\section{RESULTS AND DISCUSSION}

\subsection{Household responsibilities and financial income}

Households in both rural and urban areas ( 75 and 25 percent respectively) were characterised by specific gender divisions of labour. Echoing research by Foell et al. [8], women in the study area play a significant role in social reproduction at the household level. In contrast to the situation in many other areas of Africa [11], however, women in the study sites have significant responsibility for household budgets and their duties include fuel purchase along with more commonly observed tasks such as the preparation of household food and firewood collection. Women were also found to have an influence on stove purchases with requests for less smoky stoves sometimes being granted and usually at least being considered by male heads of household, as noted in the quotes below.

"A woman....ordinarily cooks in the kitchen and knows her needs so the husband obeys any decision the woman makes concerning her kitchen" (Male Focus group one: Study site 1, 2015)

"my husband understands that I am the one who is always in the kitchen and would be in a better position to understand my needs so when I ask him to purchase anything in the kitchen including a stove he quickly obliges” (Female Focus group one: Study site 3, 2015).

This type of shared responsibility for household decision-making enabled women to use more energy efficient cooking devices to reduce the drudgery of firewood collection. It was interesting to note that that even respondents from low-income households shared household duties along gender lines, as indicated in the following quotes.

“......these women are unemployed in the sense that they have zero income so we need to do what we can to help them" (Male interview one: Study site 1,2016).

“....we need to support them. I don't know what the government is doing” (Male interview one: Study site 3,2016).

With regard to income as a constraint on ICS uptake, our study identified low-income and high-income households to understand how different groups share household responsibilities. Drawing on the questions used in the DHS household survey, each respondent was asked the number of household income earners and dependents, and the amount of household expenditure on fuels and rent. Direct observation was also employed to monitor the presence of other indicators of socioeconomic status including televisions, refrigerators, motorcycles, other vehicles and mobile phones. This enabled us to place households into low and highincome categories. Low income households tended to have more dependents and quite low levels of financial income and comprised 70 percent of households in this study. High-income households tended to have more income earners with higher energy expenditure and access to modern technology compared to low-income households. Nevertheless, even high-income households expect assistance in the form of government intervention. As one participant suggested in relation to ICS. 
“...except when the government provides these ICS free to households......even at subsidised rates there are some people in this community who may not be able to pay even at such low prices" (Male interview one: Study site 2, 2016).

\subsection{Gendered decision-making in relation to cooking}

Across the study sites, the views of many male and female respondents appears to converge with regards to who decides on the type of stove to purchase and use. As the following quotes illustrate, men are often sensitive to women's cooking requirements and are willing to make investments when women need them.

".....the purchase of an improved cookstove should be done without a woman having to ask because cooking is the primary responsibility of women.... So, if I have about N50,000 I will buy an ICS for my wife who already has a kerosene stove" (Male interview two: Study site 3, 2015).

"When you.... watch how women manoeuvre around smoke when cooking, you will appreciate them. So, in every situation I allow her to take her decision in the kitchen" (Male elder interview two: Study site 2, 2016).

"I travelled away once and my husband had to cook for the children I know what he went through and since then he periodically ask me my cooking needs" (Female, Focus group one: Study site 1, 2015).

“....You see in our culture, it is women that are cooks and not men ... I don't cook, but when my wife complained of smoke I quickly compared the two types of fuels she uses and we decided on the type she preferred" (Male interview two: Study site 2, 2016).

The views of male and female household members appeared to converge with regards to health-related concerns about exposure to smoky cookstoves. According to our data, 75 percent of respondents linked this directly to the uptake of cleaner stoves while others complained about the discomfort of heavy smoke associated with cooking on three stone fireplaces.

"my wife.....was experiencing pains in her eyes and when I took her to the hospital, I ended up spending so much money such that I have no savings again. Since then if she makes a demand in the kitchen, I quickly respond to it unless I don't have [the means to do so] " (Male focus group one: Study site 3, 2015).

"When the smoke becomes so intense we make a demand that a stove be purchased. So women are the ones that make a demand that a stove be purchased" (Female focus group one: Study site 2, 2015).

"Smoke...I am not comfortable with it when I cook with firewood on my three-stone fire-it is difficult because of smoke and I have to close the kitchen door and stay outside periodically I go back inside the kitchen to tend the fire. It is not my desire to cook on a three-stone fire but in our community I have to cook in this way since I don't have alternatives" (Female focus group one: Study site 2, 2015). 
Decisions related to firewood collection were reported to be primarily taken by women with decisions to travel in search wood fuel often made without spouses' knowledge. While appreciative of the fact that firewood collection and food preparation on three stone fireplaces are both tedious tasks for women, however, many of our male respondents felt that they should still be consulted about such trips.

"My wife doesn't search for firewood fuel because we are both vulnerable ......I have decided that we only purchase the fuel, so if she must collect for obvious reasons I should be informed" (Male interview three: Study site 3, 2016).

"not only firewood, anywhere she likes to visit as a housewife she must inform her husband. If the husband declines then she must abort the trip and remain at home" (Male focus group one: Study site 2, 2015).

These responses hints at broader gender inequalities more characteristic of studies elsewhere in Africa [34], [35] and reflect these respondents' views that women shouldn't be allowed to move around freely under the guise of firewood collection whilst abandoning other domestic duties.

\subsection{Choice of fuel influenced by the cooking device}

Household energy sources were categorised into three groups according to the energy ladder model [16]-[19], namely biomass (firewood and charcoal), transitional fuel (kerosene) and modern fuels (electricity and liquefied petroleum gas) and informed by the results from the DHS analysis. The main fuel used by households for cooking during the study was firewood and 88 percent of the respondents cook on three stone fireplaces whilst the remaining 12 percent cook on energy efficient cookstoves. In urban areas for example, it is commonplace for men to pay for fuel, while in rural areas it was usually obtained free of cost by women but its collection was associated with significant opportunity costs in the form of lost time for income generation and other productive activities as noted by our respondents:

"We mostly purchase firewood except when we travel outside the town and each of the journeys is unpleasant. Sometimes we arrive home late” (Female Focus group one: Study site 1, 2015)

"Firewood collection consumes women's time that would have been invested in other activities" (Male focus group two: Study site 2, 2015).

According to Rehfuess et al. [36], the uptake of energy efficient stoves tends to be higher in settings where fuel is mostly purchased. The second most widely used fuel reported by respondents was charcoal which is transported in bags on trucks from sites of production to various retail locations so its price is often influenced by transportation costs. Charcoal selling is an important livelihood for women in urban and rural areas [37]. The price of a bag costs between N1500 to N1650 during the dry season and N1750 to N1850 in the wet season. ( $£ 1$ was N398 at the time of fieldwork). Most charcoal is used on Abacha stoves which are rudimentary steel cooking devices introduced in Nigeria to help cushion the effect of kerosene scarcity [38]. Although not certified as energy efficient by the Standard Organisation of Nigeria (SON), they are widely liked in the study for the fact that they are 
less smoky and produce less soot than three stone fireplaces and help keep kitchens and cooking pots cleaner:

"....I discovered the Abacha stove and since then my cooking pots have remained clean. It hardly produces any smoke compared to the three-stone fire" (Female interview one: Study site 1, 2016).

Nevertheless, most households retain their three stone fireplaces with many mentioning that they 'stack' [24] a combination of different stoves according to what they are cooking, the season and the prices of different fuels:

"most women use multiple cooking devices to prepare meals at one occasion and would give you pertinent reasons to back up their actions" (Male interview two: Study site 3, 2016).

Some households stacked non-solid fuels and energy efficient stoves of the type promoted by the Global Alliance for Clean Cookstoves (GACC) alongside traditional three stone fireplaces. Nevertheless, the proportion of households that used electricity and LPG for cooking was much lower than expected even in urban areas and appeared to have declined over time. Echoing research by Oyedepo [27], our finding indicated that the seasonality of electricity supply had caused some households to abandon their electric stoves and resort to either kerosene stoves or three stone fireplaces:

"there will be a need to make alternative arrangements since electricity supply has been seasonal over time. In such situations, the traditional stove has a role to play that is very essential” (Male interview one: Study site 1, 2016).

"I have an...electric stove but we hardly enjoy electricity in our community. I don't know of other places, even when they do get supply, it only lasts for few hours so we don't use the stove" (Female interview two: Study site 2, 2016).

Echoing findings by Adkins et al. [14], decisions on the type of stove to use from household 'stove stacks' tend to be made by women. When faced with the challenge of preparing food for a large family, many respondents said they tended not to use LPG stoves because they regard them as slower to cook with than traditional three stone fireplaces.

\section{CONCLUSION}

Data from urban, peri-urban and rural areas in Benue State, North Central Nigeria indicate that gender divisions of labour and intra-household decision making have significant influence on fuel and cookstove use. As Dutta [11], suggests, women often find it difficult to access basic resources such as financial credit partly because of the time they spend in firewood collection so their capacity to make a shift to clean cooking systems can be limited. In households where decision-making power is shared fairly evenly between spouses, women sometimes feel able to request the purchase of stoves that use cleaner fuels that reduce the inconveniences and health impacts of smoke whilst helping to keep their cooking pots and kitchens tidy. These findings contrast with the energy ladder model which focuses on household income levels rather than on who controls this income and the extent to which responsibility for spending is shared between spouses. As women with significant input into household-based decision-making have potential to influence a transition to modern fuel and energy efficient cooking devices, we argue that Nigerian stakeholders need to pay more 
attention to understanding and taking on board context-specific gender relations when seeking enhance energy and stove development policies.

\section{ACKNOWLEDGEMENTS}

The authors' gratitude goes to DfiD and the Engineering and Physical Sciences Research Council's grant EP/L002639/1: "Understanding the barriers to the introduction and uptake of clean/improved cookstoves in Sub-Saharan Africa" for financial assistance during the fieldwork.

\section{REFERENCES}

[1] Kabeer, N., Gender Mainstreaming in Poverty Eradication and the Millennium Development Goals: A handbook for policy-makers and other stakeholders, Commonwealth Secretariat, p. 4, 2003.

[2] GACC (2017a). 'About' Online. http://cleancookstoves.org/about/. Accessed on: 28 Mar 2017.

[3] International Energy Agency (IEA). World Energy Outlook Online. https://www.iea.org/publications/freepublications/publication/WEO2014.pdf Accessed on: 27 Sep. 2016.

[4] The DHS Program, Demographic and Health Survey Online. http://www.statcompiler.com/en/ Accessed on: 8 Feb. 2017.

[5] Smith, K.R. et al., Public health benefits of strategies to reduce greenhouse-gas emissions: health implications of short-lived greenhouse pollutants. The Lancet, 374, 2091-2103, 2009.

[6] Bonjour, S. et al., Solid fuel use for household cooking: country and regional estimates for 1980-2010. Environ Health Perspect, 121, 784-90, 2013.

[7] Bruce, N., Pope, D., Rehfuess, E., Balakrishnan, K., Adair-Rohani, H. \& Dora, C., WHO indoor air quality guidelines on household fuel combustion: Strategy implications of new evidence on interventions and exposure-risk functions. Atmospheric Environment, 106, 451-457, 2015.

[8] Foell, W., Pachauri, S., Spreng, D. \& Zerriffi, H., Household cooking fuels and technologies in developing economies. Energy Policy, 39, 7487-7496, 2011.

[9] Bruce, N., Perez-Padilla, R. \& Albalak, R. Indoor air pollution in developing countries: a major environmental and public health challenge. Bulletin of the World Health Organization, 78, 1078-1092, 2000.

[10] Ezzati, M., Saleh, H. \& Kammen, D.M., The contributions of emissions and spatial microenvironments to exposure to indoor air pollution from biomass combustion in Kenya. Environ Health Perspect, 108, 833-839, 2000.

[11] Dutta, S., Energy as a key variable in eradicating extreme poverty and hunger: A gender perspective on empirical evidence on MDG\# 1 DFID Discussion paper. London: UK: Department for International Development, 2005.

[12] Kelekar, G. \& Nathan, D., Gender relations and the energy transition in rural Asia. Energia News, 8, 22-13, 2005.

[13] Bolaji, B.O., Effects of Unsustainable Use of Biomass Energy for Cooking and Strategies for Their Reduction in Developing Countries. Developing Country Studies, 2, 19-25, 2012.

[14] Adkins, E., Tyler, E., Wang, J., Sirriri, D. \& Modi, V., Field testing and survey evaluation of household biomass cookstoves in rural sub-Saharan Africa. Energy for Sustainable Development, 14, 172-185, 2010. 
[15] Treiber, M.U., Grimsby, L.K. \& Aune, J.B., Reducing energy poverty through increasing choice of fuels and stoves in Kenya: Complementing the multiple fuel model. Energy for Sustainable Development, 27, 54-62, 2015.

[16] Leach, G., The energy transition. Energy policy, 20, 116-123, 1992.

[17] Barnes, D.F. \& Floor, W.M., Rural energy in developing countries: A challenge for economic development 1. Annual Review of Energy and the Environment, 21, 497530, 1996.

[18] Barnes, D.F. \& Qian, L., Urban Interfuel Substitution, Energy Use, and Equity in Developing Countries: some preliminary results. The World Bank, 1992.

[19] Hosier, R.H. \& Kipondya, W., Urban household energy use in Tanzania: prices, substitutes and poverty. Energy Policy, 21, 454-473, 1993.

[20] Smith, K.R., Mehta, S. \& Maeusezahl-Feuz, M., Indoor air pollution from household use of solid fuels. Comparative quantification of health risks: global and regional burden of disease attributable to selected major risk factors, 2, 1435-1493, 2004.

[21] Cecelski, E., Energy, development and gender: Global correlations and causality. Energia International Network on Gender and Sustainable Energy, 2005 Online. $<$ www.energia.org/crgge. Accessed on: 12 May 2015.

[22] Masera, O.R., Saatkamp, B.D. \& Kammen, D.M., From linear fuel switching to multiple cooking strategies: a critique and alternative to the energy ladder model. World development, 28, 2083-2103, 2000.

[23] Joon, V., Chandra, A. \& Bhattacharya, M., Household energy consumption pattern and socio-cultural dimensions associated with it: A case study of rural Haryana, India. Biomass and Bioenergy, 33, 1509-1512, 2009.

[24] Parikh, J.K., Gender issues in energy policy. Energy Policy, 23, 745-754, 1995.

[25] Anozie, A., Bakare, A., Sonibare, J. \& Oyebisi, T., Evaluation of cooking energy cost, efficiency, impact on air pollution and policy in Nigeria. Energy, 32, 1283-1290, 2007.

[26] NBS/CBN/NCC., Annual socio-economic survey on Nigeria. Abuja, Nigeria: Nigeria Bureau of Statistics-Central Bank of Nigeria-Nigerian Communication Commission colloborative study 2011 Online: http://www.nigeriastat.gov.ng/nbslibrary/nbsannual-abstract-of-statistics. Accessed on: 10 May 2015.

[27] Oyedepo, S.O., On energy for sustainable development in Nigeria. Renewable and Sustainable Energy Reviews, 16, 2583-2598, 2012.

[28] The Nations Online Project Online. http://www.nationsonline.org/maps/nigeriaadministrative-map.jpg Accessed on: Sep. 2015.

[29] Keay, R.W.J., Trees of Nigeria, Clarendon Press, 1989.

[30] Dapo, B. \& Emmanuel, O., Charcoal versus other domestic cooking fuels: survey of factors influencing consumption in selected households of Benue State, Nigeria. Journal of Sustainable Development in Africa, 15, 25-37, 2013.

[31] Marshall, M.N., Sampling for qualitative research. Family practice, 13, 522-526, 1996.

[32] Oppenheim, A.N., Questionnaire Design, Interviewing and Attitude Measurement, pp. 47, 1999.

[33] Pannucci, C.J. \& Wilkins, E.G., Identifying and avoiding bias in research. Plastic and reconstructive surgery, 126, 619, 2010.

[34] Hausmann, R., Tyson, L.D., Bekhouche, Y. \& Zahidi, S., The global gender gap index 2012. World Economic Forum, 2013.

[35] Wamukonya, N., A critical look at gender and energy mainstreaming in Africa. Draft Paper distributed at the "gender perspectives in sustainable development" side event organized by the United Nations Division for the Advancement of Women and the 
Women's Environment and Development Organizations (UNDESA/DAW-WEDO) at Prep Com III. A panel discussion held on April 3, 2002.

[36] Rehfuess, E.A., Puzzolo, E., Stanistreet, D., Pope, D. \& Bruce, N.G., Enablers and barriers to large-scale uptake of improved solid fuel stoves: a systematic review. Environmental health perspectives, 122, 120-130, 2014.

[37] Ali, O.J. \& Victor, M.A., Assessment of Socio-economic Factors Affecting Household Charcoal use in Makurdi Urban Area of Benue State, Nigeria. Journal of Environmental Research and Management 3(7). pp. 0180-0188, 2013.

[38] Uzoma, C.D., Indigenous people's right crusader Online. http://www.org.uy/oldsite/ bulletin/106/nigeria/htm/. Accessed on: 3 May 2015. 